\title{
ABORDAGEM (MAL)HUMORADA: QUADRINHOS DE HUMOR EM LIVROS DIDÁTICOS DE INGLÊS
}

\author{
Bad-tempered Approach: Comics in English Textbooks
}

\author{
Ilka de Oliveira MOTA \\ Universidade Federal de São Carlos \\ ilkamotaeducacao@gmail.com
}

\begin{abstract}
RESUMO: $O$ artigo traz resultados de nossa pesquisa sobre os modos de abordagem dos quadrinhos de humor em livros didáticos de inglês como língua estrangeira (LE), erigindo uma reflexão crítica sobre o livro didático, mais exatamente sobre o modo de tratamento do gênero quadrinhos de humor. Para isso, apoiamo-nos na Análise de Discurso na interface com os estudos de Freud (1905) sobre a comicidade. Analisamos dois recortes feitos a partir de dois livros didáticos de inglês que tiveram circulação na cidade de Campinas e região. Tais recortes são exemplificadores do tipo de abordagem reservada aos quadrinhos de humor, o que nos permite compreender a concepção de língua e de ensino que atravessam o corpus em análise. PALAVRAS-CHAVE: Livro Didático; Inglês; Humor; Abordagem.
\end{abstract}

\begin{abstract}
The article brings results of our research on the ways of approaching comics in English textbooks as a foreign language (FL), raising a critical reflection on the textbook, more precisely on the approach of the genre of humor. For this, we rely on Discourse Analysis in the interface with Freud's studies (1905) on comicity. We analyzed two cutouts made from two English textbooks that circulated in the city of Campinas and region. Such cutouts exemplify the type of approach reserved for comics, which allows us to understand the conception of language and teaching that cross the corpus under analysis. KEYWORDS: Textbooks; English; Humor; Approach.
\end{abstract}

\section{INTRODUÇÃO}

Os livros didáticos de inglês sempre exerceram uma espécie de fascínio em nossa constituição identitária, seja como aluna, seja como docente. Na posição de pesquisadora, esse instrumento linguístico é, além de objeto de desejo, um objeto de pesquisa, de análise. Portanto, compreender como ele funciona, como aborda determinados gêneros discursivos é uma de nossas metas. Na mesma direção de interesse, estão os quadrinhos de humor. 
Estes se mostram profícuos não somente para a compreensão de seu funcionamento, mas como objeto de ensino, principalmente no processo de ensino-aprendizagem de uma língua estrangeira, em nosso caso, o inglês.

Para compreender os modos de abordagem dos quadrinhos por livros didáticos (LDs) de inglês como LE, apoiamo-nos na Análise de Discurso, campo do conhecimento esse que permite trabalhar com a espessura material dos objetos.

\section{MODOS DE FUNCIONAMENTO DOS LIVROS DIDÁTICOS}

Segundo os trabalhos desenvolvidos por Coracini (1995; 1999), o livro didático é compreendido como o lugar de inscrição de poder e saber, na medida em que ele é atravessado pelo discurso da ciência, o que lhe garante, pois, um caráter de verdade absoluta. Esse caráter de verdade atribuído ao LD garante-lhe, também, autoridade (SOUZA, 1999, p. 114).

Coracini (2003, p. 203) tem compreendido o livro didático como "autoridade legitimada para dizer o que ensinar", e faz isso recortando o saber científico e impondo-o como verdade total e inquestionável. Esse caráter de autoridade imputado ao livro didático “encontra sua legitimidade na crença de que ele é depositário de um saber a ser decifrado, pois supõe-se que o livro didático contenha uma verdade sacramentada a ser transmitida e compartilhada" (SOUZA, 1999, p. 27).

Em virtude de seu caráter de verdade, o livro didático continua a servir como um guia para aulas de muitos professores. Nas palavras de Ramos (2009, p. 173), o livro didático é usado por muitos professores da escola pública "como suporte pedagógico para planejar suas aulas e/ou fonte para seleção de textos e atividades, ou mesmo como suporte teórico para o professor".

No plano do imaginário, espaço de organização dos sentidos, o LD é representado como "o lugar do saber definido, pronto, acabado, correto" (SOUZA, 1999, p. 27), talvez seja essa a razão pela qual, por muito tempo, ele tenha sido concebido como "fonte última" e, em alguns casos, "única" de referência. Pelo seu modo de configurar o conhecimento, isto é, os conteúdos didático-pedagógicos legitimados institucionalmente pelo discurso escolar e pela sociedade em geral, o LD vem, ao longo da história, apresentando-se, segundo Ramos (2009, p. 176), como uma "forma conveniente de apresentar o material para os alunos", uma vez que ele dá impressão de garantia de "consistência e continuidade a um curso; dá aos alunos um senso de sistema, coesão e progresso, e ajuda os professores a preparar suas aulas". Tais sentidos construídos historicamente sobre o LD estão diretamente 
relacionados com o estatuto do autor do LD em nossa sociedade. Além de representar um lugar de autoridade no imaginário social, autoridade esta garantida pelo conhecimento que detém ou que é suposto que detenha - daí a ideia de entidade todo-poderosa, detentora do saber, "fonte de transmissão quase que exclusiva de conhecimento" (SOUZA, 1999, p.58), o autor de LD é significado na/pela memória discursiva como aquele que tem "competência" de selecionar, recortar, formatar e hierarquizar os conteúdos com "clareza didática”, tal como Souza (1999, p. 29) escreve,

A noção de autor do livro didático e que faz parte da crença predominante entre professores o configura enquanto aquele que é responsável pelo que "diz" no livro didático; pelo conteúdo que ele seleciona; pela forma de organização do conteúdo selecionado e pela forma de apresentação desse conteúdo, a sua competência enquanto autor é, geralmente, medida pelo caráter de clareza didática, avaliada em termos da linguagem utilizada.

Vale dizer que o modo de selecionar, recortar, formatar e hierarquizar o conhecimento imprime uma "cara" ao livro didático, permitindo-nos reconhecê-lo como tal64. Em resumo, há, de um lado, uma configuração específica, que garante ao LD uma "cara de livro didático" (tipos de textos e seu modo de configuração nas páginas, o tipo de práticas didático-pedagógicas, o conteúdo, etc.), e, de outro, uma escrita elaborada, com uma linguagem e metalinguagem específicas, didatizadas (ou com "clareza didática", no dizer de Souza, 1999, p. 58), de modo a atender ao ideal que atravessa o discurso didáticopedagógico, qual seja: clareza, concisão, unidade e não-contradição. Isso se dá porque todo discurso obedece a uma lei de raridade ou rarefação (FOUCAULT, 1969), pois nem tudo pode ser dito por qualquer um, em qualquer lugar e de qualquer modo.

A didatização está intimamente relacionada com os modos de controle dos sentidos e, fundamentalmente, com o modo de funcionamento do discurso didático-pedagógico. Ou seja, a didatização (seu efeito) é garantia, imaginária, de manutenção das posições de sujeito (professor, aluno, autor) e das relações (de força) de sentido que se constituem no espaço semanticamente normal dos LDs. Noutras palavras, ela é um meio de controlar a produção discursiva (a produção dominante dos sentidos) e garantir a posição de cada um dos sujeitos suscitada por essa ordem do discurso. A necessidade de administrar a relação dos sujeitos escolares com os sentidos - relação imaginariamente sem equívocos e contradição - coloca em funcionamento o que Pêcheux denomina de "divisão social do trabalho da leitura" (PÊCHEUX, 1980). A alguns é dado o direito de interpretar, a outros o direito de reproduzir, a alguns o direito de perguntar de uma certa forma (com clareza 
didática, como é o caso do discurso didático-pedagógico, por exemplo) e a outros, de responder também de uma certa forma e não de outra. A divisão social do trabalho de leitura está intrinsecamente relacionada com a exterioridade, tal como Foucault (1969, p. 153) escreve: “"'não importa quem fala”, mas o que ele diz não é dito de qualquer lugar. É considerado, necessariamente, no jogo de uma exterioridade". Portanto, a clareza didática (a didatização) coloca em funcionamento o lugar, os sujeitos envolvidos nele e suas imagens e, finalmente, as formas ritualizadas que envolvem todo e qualquer processo de interlocução.

Vale dizer ainda que, enquanto uma das regularidades do discurso didáticopedagógico, a didatização reforça a ideia de que, de um lado, o aluno-leitor está no "grau zero do conhecimento", e, de outro, que o autor é o detentor do conhecimento, da verdade. Esta é, pois, uma imagem historicamente construída e socialmente compartilhada entre os sujeitos escolares (professores, alunos e autores de livros didáticos principalmente) ${ }^{1}$.

Nesse jogo imaginário que estabelece a cada sujeito escolar uma posição determinada por meio do grau de conhecimento, o professor, cuja posição é legitimada pela instituição escolar, tem sua voz reconhecida pelo uso que faz do LD (MOTA, 2018). Mais precisamente, muito do que o professor ensina é, muitas vezes, resultado da reprodução do que está no LD, ou seja, é reprodução da fala do autor do LD. O professor seria, então, porta voz dos conteúdos presentes no e legitimado pelo LD, e também portador dessa forma didatizante de "passar" o conhecimento aos alunos. Paradoxalmente, embora tenha comumente a sua voz apagada (CORACINI, 1995; 1999), o que o professor ensina é tomado como lei, é palavra de ordem por conta da "apropriação" que faz do LD. Isso acontece porque tanto o LD como o discurso didático-pedagógico apresentam-se, como dissemos anteriormente, como sendo a verdade: "tudo o que é dito ou escrito corresponde à verdade, verdade sobre os fatos, sobre a natureza, os objetos, sobre o processo de ensino-aprendizagem, sobre a língua...” (CORACINI, 2003, p. 200).

\footnotetext{
${ }^{1}$ Analisando as formas que assumem as perguntas e as respostas dos alunos no contexto de aprendizagem de línguas, Coracini $(1995$, p.75) observa que "os alunos buscam responder exatamente ao que o professor deseja; raramente, assumem uma resposta diferente e a discutem entre si ou com o professor", e a autora continua, afirmando que "tal atitude (...) decorre, evidentemente, das imagens que os alunos [e acrescentaríamos professores e autores de LDs] vão construindo ao longo dos anos de escolarização do que seja ser professor, do que seja ser aluno, do que seja ensinar/aprender a língua materna, do que seja ensinar/aprender a língua estrangeira, do que seja ler, o que implica também, ainda que pressuposta, uma certa concepção de linguagem".
} 


\section{O CAMPO DA COMICIDADE}

Para discorrer sobre o campo da comicidade, é importante trazer para a consideração o conceito de língua adotado. Discursivamente, a língua tem como fator estruturante a falta, o que a torna um sistema relativamente autônomo, não fechado em si mesmo. A noção de sistema linguístico é uma das mais importantes para a abordagem discursiva, uma vez que mostra a importância das condições de produção do discurso: a produção simbólica do homem não pode ser compreendida apenas à luz dos conhecimentos linguísticos, mas do contexto histórico-social e cultural em que ela se dá. Assim, a linguagem não é simplesmente um meio de comunicação, mas forma de manifestação do poder de indivíduos ou grupos (FOUCAULT, 1979 [2001]). O indivíduo, interpelado em sujeito pela ideologia, em vez de entidade homogênea e centrada, é sujeito ao discurso e às restrições sociais. Assim, os sentidos e seus efeitos e a subjetividade não podem ser pensados fora dessa complexa malha que articula a língua ao histórico-social e cultural.

Ao mesmo tempo em que há restrições sociais, há a resistência, que se faz, entre outros, pelo recurso da língua enquanto sistema significante, simbólico que produz efeito a partir de sua inscrição na história.

A esse respeito, o campo da comicidade, que se utiliza em grande medida do sistema linguístico, mostra-se um campo fértil onde podemos observar pontos de resistência do sujeito. É por isso que a noção de língua é uma das mais importantes para uma abordagem discursiva da linguagem, à medida que ela constitui a condição de possibilidade do discurso: possibilidade de coerção, mas, também, de conflitos, de resistência.

Como afirma Ferreira (2000, p. 35), é a partir dessa compreensão que avançam as noções de "falha", "heterogêneo", "borda" e "impossível", pontos em que o discursivo e o linguístico são tecidos um dentro do outro. O campo da comicidade explora recursos expressivos presentes na própria estrutura significante do sistema linguístico (duplicidade de efeitos discursivos, ironia, ambiguidade, equívoco, etc.). Isso significa que o campo da comicidade irrompe na materialidade da língua, atestando, pois, o seu caráter oscilante, desestabilizador. Neste sentido, ele é um modo de libertar a língua das estruturações lógico- matemáticas e da sisudez do formalismo a que é muitas vezes submetida, como afirma Ferreira (2000, p. 111). O real da língua, o chiste, o trocadilho, a charada, os jogos de palavras, o humor é feito com a língua e sobre ela, por isso são reveladores do seu caráter oscilante, paradoxal e contraditório. Afirma, ainda, com base em Judite Milner, que o riso surge na medida em que algum saber linguístico é violado. Nesse sentido, "o riso irrompe", segundo a autora, "pelo estranhamento, pelo aspecto bizarro de uma 
construção, ou ainda pela sua completa incongruência" (2000, p. 110).

Há um sentido de comicidade já naturalizado que continua ressoando em nosso meio social: o que a associa a "diversão" (brincadeira, nonsense) em oposição à "seriedade" (trabalho). Vale dizer, essa ideia está fortemente presente na discussão promovida por Souza (2001), na qual enfatiza a importância de se trabalhar a competência humorística no contexto da sala de aula. Em sua afirmação, "o humor aumenta o aprendizado porque os alunos relaxam, divertem-se (...). Além disso, [ele] reduz o estresse psicológico" (SOUZA, 2001, p. 451); temos aqui uma concepção de humor ancorada em uma perspectiva psicológica e pragmática. O humor se reduziria a um tipo de objeto de conhecimento que serviria apenas para relaxar e divertir o leitor depois de cumprir uma determinada tarefa didático-pedagógica. Identificamos aí uma oposição entre o sério e a brincadeira, oposição esta estabelecida por uma divisão institucional dos sentidos, própria de um mundo semanticamente normal, normativo e estabilizador. Tudo se passa como se a brincadeira fosse, ela mesma, uma atividade isenta de poder, em contraposição ao sério (ou à realidade).

Compreendemos, nesta pesquisa, que o humor, em geral, não é um objeto já dado, transparente, que serve como mero instrumento para relaxar os ânimos, mas um objeto simbólico atravessado pela história, construção significante de culturas e sociedades específicas. Enquanto manifestação estética, o humor é ainda o espaço de inscrição de forças que estão em jogo no aparelho psíquico (desejo, prazer, agressividade, enfim, energias psíquicas que constituem o sujeito de linguagem, sujeito do inconsciente).

No contexto didático-pedagógico, o campo da comicidade seria, segundo o discurso didático-pedagógico, um discurso meramente lúdico e que não requer maior exercício intelectual. Noutros termos, pressupõe-se que a diversão, a brincadeira, o jogo, não constituem um exercício intelectual, trabalho com os sentidos. Da perspectiva desta pesquisa, o humor se constitui como uma espécie de "arma" e de defesa da subjetividade. Quando afirmamos que o humor não é "mera brincadeira", mas, sim, um exercício intelectual, estamos dizendo que ele implica relações subjetivas, sociais, culturais e ideológicas; por isso, ele não deve ser pensado como algo inocente e simples. Embora ele esteja associado ao lúdico, ao prazer e ao poético, isso não faz dele uma "mera brincadeira"; numa abordagem psicanalítico-discursiva do campo da comicidade, a questão é mais complexa, pelas razões que já expusemos: há relações subjetivas e sóciohistóricas implicadas na produção do prazer e da poeticidade cômicas.

O discurso cômico põe em jogo questões fortes envolvendo a relação do sujeito com os sentidos e o mundo. Este modo de compreendê-lo apóia-se em estudos da psicanálise 
(FREUD, 1905), da análise do discurso (POSSENTI, 1998; PÊCHEUX, 1983; GADET \& PÊCHEUX, 1981). Segundo Pêcheux e Gadet (2004, p. 94), o humor (aqui o termo significa todo o campo da comicidade) e a poesia não são o "domingo do pensamento [...] mas pertencem aos meios fundamentais de que dispõe a inteligência política e teórica...". Os autores não só sustentam que a língua é capaz de humor e de poesia, como defendem, citando Brecht, que é "difícil aderir ao Grande Método (a dialética) quando não se tem humor": a história, com suas contradições, requer uma posição humorada, aberta ao equívoco e ao disparate.

\section{FUNCIONAMENTO DISCURSIVO DE TEXTOS QUADRINIZADOS}

A arte quadrinizada (tirinhas e histórias em quadrinhos) é heterogênea em sua constituição enquanto matéria simbólica (MOTA, 2018). Ela se constitui na articulação com, pelo menos, duas outras linguagens, que também são heterogêneas entre si: a pictórica e a cinematográfica.

Com relação à arte pictórica, entram em relação à gestualidade dos personagens, $\mathrm{o}$ desenho (o próprio traçado), a(s) forma(s), a(s) cor(es), o tamanho dos objetos desenhados, etc., já à arte cinematográfica, a influência de procedimentos cinematográficos no processo de produção dos quadrinhos pode ser identificada, por exemplo, na possibilidade de diferentes recortes e enquadramentos, estabelecendo uma espécie de escala dos planos, que vai do mais aberto, o chamado Plano Geral, até os mais fechados, o primeiríssimo plano, que mostra só o rosto, e o Plano de Detalhe, que recorta uma parte do corpo ou um objeto.

Do ponto de vista do discurso, os quadrinhos são textos, uma vez que estão intimamente relacionados com a exterioridade, ou seja, com o contexto sócio-histórico e ideológico em que são produzidas. Noutras palavras, são objetos que trazem em seu bojo diferentes gestos de interpretação, diferentes posições do sujeito, diferentes formações discursivas, distintos recortes de memória, em uma palavra: distintas relações com a exterioridade.

Para Mendonça (2005), o famoso quadrinista Eisner denomina esse modo de manifestação linguageira como "arte sequencial", devido ao fato de sua estruturação composicional se caracterizar pela justaposição de quadros sequenciais. O autor utilizase da denominação "quadrinhos" para se referir tanto às tirinhas quanto às histórias em quadrinho, que é a mesma posição adotada por nós neste trabalho. 
Os quadrinhos, como o próprio nome indica, são um conjunto e uma sequência. $\mathrm{O}$ que faz do bloco de imagens uma série é o fato de que cada quadro ganha sentido depois de visto o anterior; a ação contínua estabelece a ligação entre as diferentes figuras. Existem cortes de tempo e espaço, mas estão ligados a uma rede de ações lógicas e coerentes (KLAWA; COHEN, 1972, p. 110).

A título de esclarecimento, a diferença entre tirinhas e histórias em quadrinhos é que enquanto aquelas são mais sintéticas, porque constituídas de até cinco quadros aproximadamente, quadros estes geralmente justapostos a uma pequena narrativa de caráter humorístico, estas, por sua vez, são narrativas mais longas, caracterizadas pela justaposição de várias sequências de quadros, resultando, comumente, em uma narrativa com uma progressão ao nível do imaginário: com começo, meio e fim. Na tirinha, também há narrativa (narratividade), mas ela se constitui diferentemente. A síntese, que se dá por meios de recursos expressivos da língua, tais como jogos de palavras, enunciados chistosos, entre outros, e do universo imagético (desenho, palavras iconizadas e onomatopaicas), parece ser uma de suas regularidades.

Embora apresentem essa diferença em sua configuração, ambas as materialidades são textos bastante complexos do ponto de vista de sua significação. Complexos, porque, para se constituírem como tais, organizam-se a partir de dois planos: o verbal (linguístico) e o não-verbal (imagens visuais) atravessados por diferentes discursos, sem contar que ambas significam na e pela discursividade cômica. Noutras palavras, ambos os planos se caracterizam por sua inscrição no campo da comicidade. Por isso, neste trabalho, referirnos-emos tanto às tirinhas quanto às histórias em quadrinho como QHs, pelo fato de nosso corpus de pesquisa ser constituído tanto por tiras quanto por histórias em quadrinho conjuntamente.

Tal como comenta Cirne (1972, p. 12), “os quadrinhos são menos simples do que aparentam". Isto porque eles apresentam um modo de significação específico, o que implica, necessariamente, uma forma particular de leitura. Nas palavras de Cirne (1972, p. 15):

[...] não se pode ler uma estória quadrinizada como se lê um romance, uma obra plástica, uma gravação musical, uma peça de teatro, ou até mesmo uma fotonovela ou um filme. São expressões estéticas diferentes, ocupam espaços criativos diferentes [...] Embora haja um denominador comum para a leitura que se preocupa com manifestações e discursos artísticos, existem leituras particulares para cada prática estética. 
Isso se dá porque a materialidade significante não é indiferente aos sentidos. Noutros termos, as diferentes materialidades simbólicas não significam indiferentemente, já que são sempre "diferentes relações com os sentidos que se instalam. São diferentes posições do sujeito, são diferentes sentidos que se produzem. (...) Há sentidos que precisam ser trabalhados na música, outros, na pintura, outros na literatura, para que signifiquem consistentemente" (ORLANDI, 1995).

O texto quadrinizado é índice de que não há apenas um sistema de signos (o verbal). O que há é um imbricamento de diferentes naturezas sígnicas que impõem, ao leitor, um modo de leitura específico. Ou seja, o modo de funcionamento do texto quadrinizado, tal como afirma Cirne (1972) na citação acima, traz um modo particular para o olhar do leitor, devido, entre outras coisas, à sintaxe que lhe é própria. A ordem sintática que o caracteriza (justaposição de quadros sequenciais, sucessivos (re)cortes, zoom, espaço off, etc.) afeta o gesto de interpretação do leitor, afeta os sentidos, ordem esta atravessada por diferentes discursividades.

É por tudo isso que o universo linguageiro dos textos de quadrinhos constitui um material rico para a análise e compreensão das várias linguagens que suscitam.

$\mathrm{Na}$ seção seguinte, apresentaremos dois recortes de quadrinhos justapostos a atividades didáticas referentes à língua e à interpretação de texto em língua inglesa. Às atividades estamos chamando de práticas pedagógicas, uma vez que têm como objetivo ensinar conteúdos referentes à língua inglesa.

\section{UMA ANÁLISE DISCURSIVA DE TEXTOS QUADRINIZADOS JUSTAPOS- TOS A PRÁTICAS PEDAGÓGICAS}

Para o que nos importa tratar, metodologicamente, os discursos que compõem o corpus são lidos, analisados, enfim, tratados não em sua origem nem neutralidade, mas "no jogo de sua instância" (FOUCAULT, 1969 [1972: 28-31]). É isso justamente que esperamos do dispositivo: que ele nos permita trabalhar não em uma posição neutra, mas relativizada em face da interpretação: é preciso, pois, o atravessamento do efeito de transparência da linguagem, da literalidade do sentido e da onipotência do sujeito. Espera-se que esse dispositivo invista na opacidade da linguagem, no descentramento do sujeito e no efeito metafórico, ou seja, no equívoco, na falha e na materialidade. Com base nessas considerações, buscamos, a seguir, descrever o corpus da presente pesquisa.

A título de esclarecimento, em nosso trabalho de doutoramento, os QHs presentes nos LDs de inglês como LE pesquisados variaram em "autênticos", isto é, quadrinhos 
que têm circulação social e que são transferidos para o contexto didático-pedagógico, isto é, que passaram por um processo de "didatização e/ou pedagogização", e em "nãoautênticos". Neste último caso, aos quadrinhos produzidos exclusivamente para os LDs de inglês, chamamos "comicidade pedagógica". Como o próprio nome indica, tratase de um tipo de comicidade produzida, sob encomenda, exclusivamente para o LD e orientada, por conseguinte, para atender às exigências do conteúdo programático do LD.

O quadrinho a seguir, presente no LD1, traz uma cena em que pai e filha conversam sobre o relacionamento amoroso da filha.

\section{Recorte 1:}

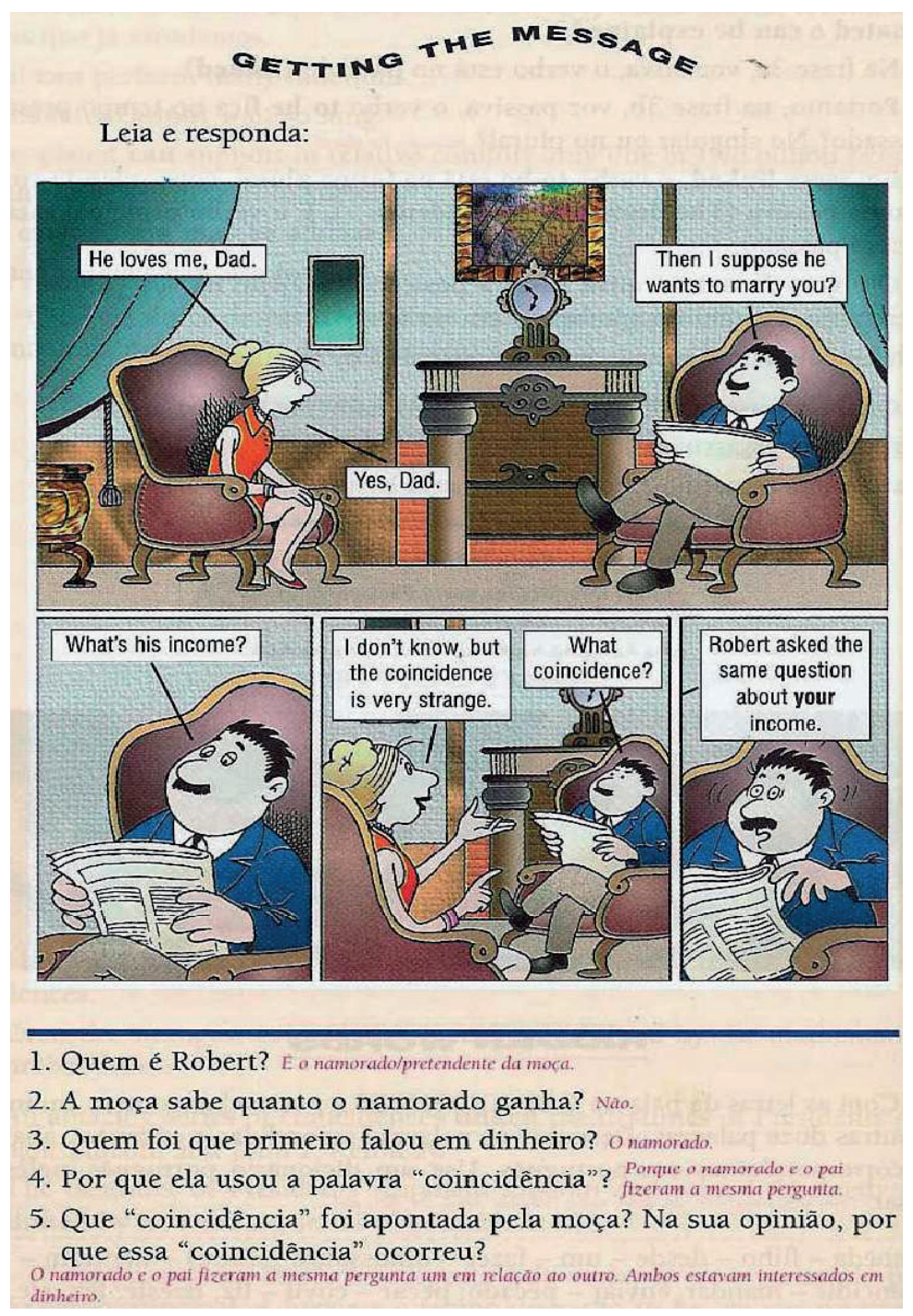

Fonte: Marques (1999). 
O quadrinho acima encontra-se na seção "Getting the message", seção que finaliza a unidade. Como se pode ver, o eixo norteador da comicidade está no jogo (irônico) instaurado pelo jogo de sentidos que a palavra income (e coincidence também, como veremos) permite estabelecer na leitura. O sentido da palavra income para pai e para namorado/pretendente da filha se diferencia, o que produz prazer cômico. Atentemos ao funcionamento discursivo das práticas pedagógicas presentes no recorte abaixo, que separamos aqui para dar a elas maior visibilidade.

Note-se que as questões de 1 a 4 acima são questões conteudísticas, uma vez que é suposta a existência de um significado, no quadrinho, para cada uma delas. Trata-se de um ideal logocêntrico que atribui ao texto (às palavras) sentidos pré-determinados. Noutros termos, estamos diante de uma concepção de ensino que pressupõe que há no texto indiferente ao gênero - um significado presente, latente, "que, além de não depender do sujeito que o compreende", pode ser recuperado, descoberto ou resgatado em sua plenitude" (ARROJO, 1992, p. 68). Basta o aluno ir ao texto e "buscar" as respostas às questões formuladas pelo LD. Tais perguntas pressupõem que o sentido está colado ao texto, à letra. A imanência atribuída ao significado permite avaliar a leitura do QH "objetivamente" (ARROJO, 1992, p. 68), reforçando o tom "sério" do livro. Neste caso, a comicidade não é contemplada, isto é, em nenhum momento, faz-se referência à comicidade nem ao fato de o texto ser um $\mathrm{QH}$. A preocupação do LD1é garantir que o aluno compreenda os elementos básicos (superficiais) do texto: quem é, quem foi, por que usou. Instaura-se aí um tipo de leitura passível de ser contida no jogo alternativo de verdadeiro ou falso, uma vez que se trata de questões factuais, que requerem apenas uma compreensão superficial do texto. Mais uma vez, o jogo, a heterogeneidade, são contidos em função de um gesto de leitura normatizador, que se explica por ser o LD parte do discurso didático-pedagógico.

Embora a última questão - Que coincidência foi apontada pela moça? Na sua opinião, por que essa coincidência ocorreu? - faça alusão ao fato de que há interesses em jogo da parte de ambos os personagens da tira, ela não trata dos efeitos de comicidade instaurados no texto, o jogo de sentidos que trabalha a materialidade linguístico-imagética.

Do ponto de vista do discurso, é possível afirmar que as palavras não têm um sentido a priori, independentemente das condições de produção da leitura. Na verdade, elas significam por conta de sua inscrição em formações discursivas com as quais os leitores se identificam inconsciente e ideologicamente. Neste sentido, é certo afirmar que a palavra income, eixo norteador da comicidade, não tem o mesmo efeito de sentido nas falas do pai e do pretendente da filha. Isso se dá porque ambos ocupam posições 
discursivas distintas.

De um lado, na pergunta do pai, “What's his income?", os efeitos de sentido da palavra income recaem na sua posição ocupada no discurso, a de pai preocupado com o futuro e conforto de sua filha, posição que não é natural nem transparente, mas produto da história; de outro, a mesma pergunta enunciada pelo pretendente, que vem através da voz da filha, produz outras possibilidades de sentidos, entre as quais, o interesse nos bens vindouros que o casamento poderá lhe propiciar. Embora nas respostas (esperadas), dadas pelo livro, fique o pressuposto de que o sentido produzido pela pergunta enunciada ("what's his income?") por ambos, pai e namorado ou pretendente, é o mesmo (Resposta do autor presente no Livro do Professor: "Porque o namorado e o pai fizeram a mesma pergunta"), discursivamente, é possível afirmar que não se trata da mesma pergunta, uma vez que, com uma mesma palavra, não dizemos a mesma coisa. Nessa direção, pensamos que o efeito cômico encontra-se justamente nessa possibilidade de sentidos que uma mesma palavra pode suscitar. O jogo que o QH em questão estabelece parece ir ao encontro dessa nossa afirmação:

$[\ldots]$

Daughter: I don't know, but the coincidence is very strange. Father: What coincidence?

Daughter: Robert asked the same question about your income.

Vale aqui o levantamento de duas hipóteses a respeito da marca, em negrito, feita pelo autor no pronome possessivo YOUR. Primeira hipótese: embora o autor (na seção do livro) não faça menção aos pronomes possessivos, acreditamos que o grifo na palavra "your" é uma espécie de dica para o aluno e para o professor quanto a seu uso. Neste caso, temos a interferência direta do autor do LD no QH que fora, como dissemos, produzido para o LD. Segunda hipótese: a marca é do quadrinista, cujo objetivo é dar ênfase, através da personagem-filha, àquilo que está sendo enunciado.

Note-se que as respostas às questões 4 e 5 (cf. recorte 1), presentes no livro do professor, pressupõem um mesmo efeito de sentido produzido pela pergunta "What's his income?". Ambos, pai e namorado, fizeram a mesma pergunta ("coincidência" denunciada pela filha), mas discursivamente, com a mesma pergunta, não disseram a mesma coisa. As respostas localizadas no livro do professor funcionam no sentido de fixar umsentido, homogeneizando o que é heterogêneo e apagando o caráter material das posições de sujeito colocadas em jogo no texto humorístico. Neste sentido, no gesto de interpretação do autor do $L D 1$, não se leva em conta o caráter material das posições de sujeito colocadas 
em jogo na interlocução. Isso significa que é dada pouca atenção aos aspectos semânticos que tecem o texto, que, a nosso ver, poderiam promover deslocamentos nas redes de memória e de sentidos cristalizados. A atenção a esses aspectos permitiria a compreensão das diferentes posições discursivas postas em jogo pelo trabalho material da língua.

$\mathrm{O}$ QH a seguir foi extraído do LD2 produzido para o ensino médio. O QH traz o casal da famosa história The Gambols, George e Gaye Gambol, do inglês Barry Appleby. Trata-se de um casal feliz e de classe média. George é o provedor do lar e Gaye, por seu lado, uma típica dona de casa. As cenas retratam o dia-a-dia do casal, principalmente a paixão de Gaye pelas compras e o esforço de George em melhorar as condições de seu lar.

Recorte 2:

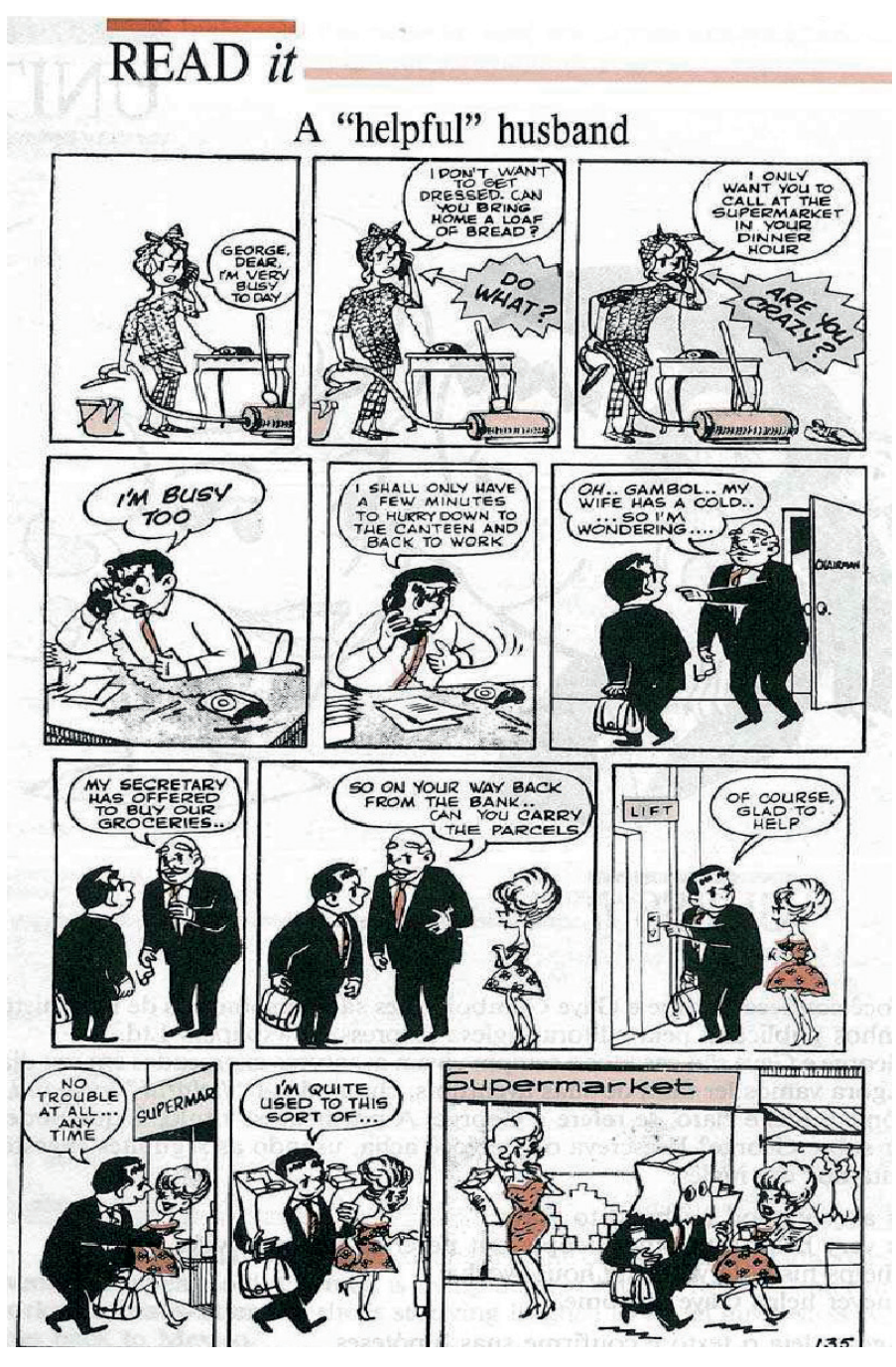

Fonte: Jelin (1999) 
Aqui, como ocorre no $\mathrm{QH}$ presente no recorte discursivo anterior, também há efeito de ironia, detectável no próprio título, $A$ "helpful" husband, em que as aspas em "helpful" desconstroem o sentido associado à palavra (típico processo irônico): enfim, o marido não é tão "helpful" assim...

Conforme Authier-Revuz (1990), as aspas são uma das formas de heterogeneidade mostrada marcada por conotação autonímica. Por esta última expressão, entendam-se os casos em que se conjugam menção e uso de palavras e/ou expressões sem rupturas no fio discursivo. No caso em questão, as aspas participam da cena enunciativa, indicando que o marido é o contrário de um homem "helpful".

No plano imagético, a graça vem do que, com Freud (1905), poderíamos chamar de cômico: o caricatural da representação do marido. Com a esposa, ele fala agressivamente, expressão raivosa; já com o patrão e a secretária, fala amavelmente, expressão de bom homem; essa mudança súbita nas expressões (plano não-verbal) e nas falas do personagem conforme o interlocutor desencadeia o efeito cômico. Trata-se de um contraste forte, radical, marcando o que Freud chamaria de "diferença de gasto", isto é, exagero de gestos e/ou discursos, caracterizando o cômico. Por fim, o saco de supermercado na cabeça para ocultar a identidade é um típico signo extremo, exagerado, caricatural, do homem que não tem onde se esconder: com a própria esposa fora rígido demais, recusando-se a ir ao supermercado; teria grandes problemas se aparecesse diante da esposa de cara lavada ao lado da secretária, como agora se encontrava. Passando com a cabeça escondida no pacote, configura-se uma situação ridícula, cômica (FREUD, 1905), causando, inclusive, o pasmo da esposa, que fica boquiaberta diante daquele estranho homem. É mais uma piada visual, típica dos QHs.

O quadrinho aparece logo no início da unidade 3. Após a sua exposição, são propostas diversas práticas didático-pedagógicas, sendo que a sua maioria é de natureza estritamente gramatical. Como é possível observar nesta unidade, o LD2 se propõe a ensinar, entre outras coisas, algumas palavras e expressões linguísticas presentes no QH, tais como o sufixo -ful e a função dos adjetivos e pronomes possessivos ("possessive adjectives and pronouns").

Com relação ao sufixo -ful, vejamos a prática 1 (JELIN, 1995), a seguir: 


\section{EXPAND it}

1. No texto você encontrou a palavra helpful. Ela é formada assim: help + ful $=$ helpful. Note que o sufixo -ful é acrescentado aos substantivos para formar adjetivos que denotam a presença do substantivo. Verifique o exemplo:

beauty (beleza) + ful $=$ beautiful (bonito)

Agora forme adjetivos dos seguintes substantivos: use, wonder, taste, care e pain.

Fonte: Jelin (1999)

Esta prática, nomeada expand it, tem como objetivo principal expandir o vocabulário do aluno. $\mathrm{O}$ autor destrincha a palavra helpful em help + ful $=$ helpful para mostrar, como se dá a sua formação, destacando que o sufixo - ful, quando acrescentado aos substantivos, forma adjetivos. Após a explicação, é proposto que o aluno forme adjetivos dos substantivos use, wonder, taste, care e pain, seguindo o modelo de helpful (help + ful).

Portanto, um dos aspectos que motiva o estudo do QH em questão é ensinar a língua como código. Apaga-se, para o aluno e para o professor, o efeito de comicidade do quadrinho. Ou seja, o implícito, a ironia, o jogo que a palavra helpful convoca, tal como aparece enunciada no quadrinho, se perdem. Dito de outro modo, a produção de sentidos (os efeitos de comicidade), que se processa a partir de um trabalho conjunto entre os planos linguístico e imagético, se perde, se apaga em favor de um ideal de língua homogeneizante, formal e literal. A ironia, garantida pelo uso das aspas em helpful, é apagada, descaracterizada, graças à abordagem linguística baseada estritamente na estrutura, no código, portanto, como o recorte acima evidencia: "Ela [a palavra helpful] é formada assim: help + ful = helpful".

Nesse modo de abordagem, identificamos uma contradição: embora seja um gênero discursivo, cuja circulação social é bastante recorrente, a abordagem que se faz dele é estritamente estruturalista. Assim, o que parece, num primeiro momento, inovação, é, na verdade, uma postura ainda ortodoxa, fechada no código.

A práticaa seguir, nomeada Study it, tem como objetivo fazer com que o aluno reconheça, no $\mathrm{QH}$, as palavras e expressões, traduzidas para o português, que estão em negrito. A proposta recai no reconhecimento, pelo aluno, das palavras e expressões presentes no QH (em inglês, portanto), que correspondem ao que está indicado, em 
negrito, nas frases, em português, presentes na atividade. Produz-se, pois, uma falsa impressão de que o aluno está em plena atividade de tradução, tradução esta concebida como um processo de correspondência. Observemos o recorte que segue:

Prática 2:

\section{STUDY it}

1. Que palavras e expressōes no texto correspondem ao que cstá destacado nas seguintes frases:

a) Você me traz um filão de pão da padaria, por favor?

b) Vamos tomar um café na cantina da escola.

c) Ela não pode fazer o trabalho? Lamento, mas eu também estou ocupado.

d) Na sua volta do banco, passe pela minha casa.

e) Ela nāo pôde vir à festa porque está resfriada.

f) Nāo há nenhum problema, eu ajudo você a fazer sua lição.

g) O diretor de minha firma está sempre me pedindo favores.

h) $\mathrm{Na}$ hora do jantar, telefone para a minha irmã.

Fonte: Jelin (1999)

As frases presentes na prática acima são tentativas de tradução de algumas palavras presentes no QH The Gambols. Nelas, encontramos, pelo menos, uma palavra presente no QH. Observamos que o livro, na Prática 2, mais precisamente a questão $a$ "Você me traz um filão de pão da padaria, por favor?", leva o aluno a estabelecer correspondência com a expressão "loaf of bread", enunciada por Gaye em "Can you bring home a loaf of bread?". Isto é, ele é conduzido a identificar em "filão de pão" [Você me traz um filão de pão da padaria, por favor?] a expressão em inglês "loaf of bread", tal como é dita por Gaye no contexto do QH. Tudo se passa como se a palavra "loaf of bread" significasse independentemente, sem a consideração do contexto em que fora produzida. Noutras palavras, o processo de interlocução em que a expressão é desencadeada é apagado. Funcionamento semelhante se dá com a questão $c$, "Lamento, mas eu também estou ocupado". Do modo como a atividade está configurada, o livro parece tomar a fala de George "I am busy too", no mesmo sentido de "Lamento, mas eu também estou ocupado.". O aluno é conduzido a identificar, nesta frase em português, o enunciado produzido por George, em inglês, como se ambos tivessem o mesmo sentido. Com base na observação do recorte em questão e da atividade proposta, não há sentimento de lamentação na fala de George, como a frase presente na PDP7 parece indicar, mas, sim, rispidez, falta de paciência, nervosismo, como se pode observar por meio do balão, da expressão facial de George e do grafismo (a letra em itálico). Portanto, "I am busy too" não significa 
nem corresponde à frase "Lamento, mas eu também estou ocupado.". Tudo se passa como se a expressão tivesse em seu interior um significado pré-existente, isto é, fora de suas condições de produção. Trata-se, a nosso ver, de uma concepção logocêntrica da linguagem, que pressupõe a possibilidade de significados independentes do sujeito (aluno e professor), do texto, da história e da circunstância da leitura. Podemos depreender disso que, na produção da prática pedagógica 2, parece funcionar uma concepção de tradução concebida como um processo de correspondência entre palavras de línguas diferentes (literalidade). A espessura material e a carga semântica, das quais as expressões "loaf of bread" e "I am busy too" são revestidas, se apagam, se esfacelam.

A atividade abaixo, nomeada Understand it, traz os personagens do recorte 18, quais sejam Gambol e Gaye, o chefe e a secretária, e suas falas, em balões "incorretos". O aluno deve rearranjar os balões conforme a fala de cada personagem da história apresentada. Leiamos a prática 3 que segue:

\section{Prática 3:}

\section{UNDERSTAND it}

1. Os quatro personagens da história $A$ "helpful" husband estāo falando sobre o que aconteceu nela, mas nosso desenhista trocou os balöes. Reescreva em seu caderno a fala que realmente corresponde a cada personagem:
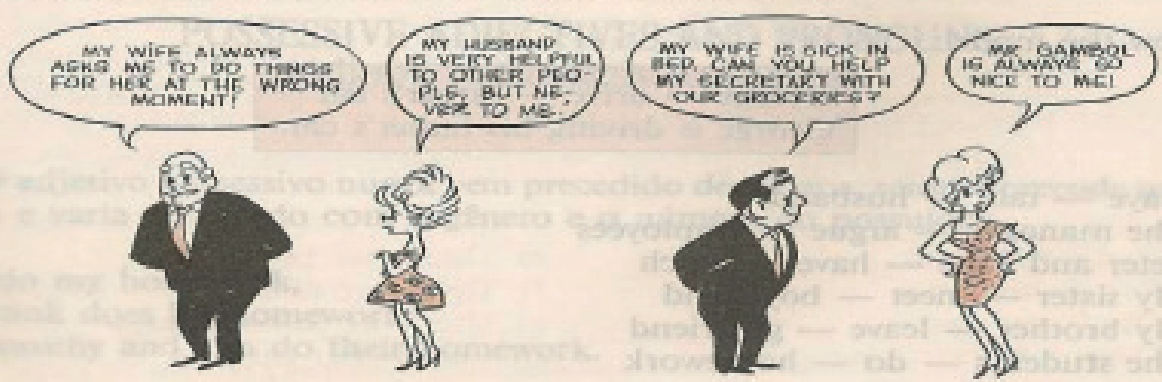

Fonte: Jelin (1999)

Note-se que esta prática didático-pedagógica, que poderia se constituir como um espaço para a compreensão das posições colocadas em jogo, ocupadas (representadas) pelos personagens do quadrinho, é reservada, unicamente, para o reconhecimento das falas dos personagens. Vale dizer, trata-se de personagens tipicamente caricaturais e estereotipadas: o chefe que manda, a secretária que sai com o funcionário, a típica esposa que limpa a casa e espera o seu marido chegar do trabalho. Basta, pois, que o aluno retorne 
ao quadrinho para que faça a correspondência ("correta") proposta pelo livro. O livro não problematiza o modo como tais posições estão representadas; ao contrário, elas são tomadas em sua evidência, tanto é verdade que é pedido que o aluno, como já dissemos, estabeleça a correspondência. Um outro modo possível de problematização dos sentidos e, fundamentalmente, de compreensão dos efeitos da comicidade, seria, por exemplo, pensar sobre o(s) (possível) efeito(s) de sentido produzido(s) pela disposição dos balões tal como aparecem na atividade. Deslocar-se-ia, pois, o objetivo da prática, permitindo que se (re) pensasse sobre o que, no $\mathrm{QH}$, produz comicidade e, consequentemente, problematizar-seiam as posições a partir das quais cada personagem enuncia. Dizendo de outro modo, ao invés de o aluno ter que simples e mecanicamente "apontar os balões que correspondem a cada personagem da pequena narrativa", ele passaria a compreender a opacidade que atravessa as posições (representações) dos personagens, de modo a compreender o que desencadeia comicidade no QH.

\section{CONSIDERAÇÕES FINAIS}

A análise empreendida mostrou que estamos diante de uma abordagem que funciona sob a égide da formalidade, da homogeneidade e da literalidade. Ainda que o campo da comicidade seja constituído pela instabilidade, pela movência, pelo jogo, a abordagem adotada tende a repelir todo o jogo de que esse campo discursivo é constituído. Por isso, não basta a simples inserção de uma infinidade de textos que têm circulação na sociedade, isto é, presentes no dia-a-dia do aluno, como é o caso dos quadrinhos. Os textos, por si mesmos, não funcionam. Se não há espaço para a historicização dos sentidos e do sujeito, para a heterogeneidade, a presença de diversos textos considerados atrativos em nada fará diferença, havendo, assim, um silenciamento que, no processo de aprendizagem, se produz sobre a memória discursiva. Noutros termos, se a concepção de ensino de língua não sofrer deslocamentos, reestruturações de toda ordem, os quadrinhos, assim como outros gêneros textuais, continuarão a ser um lugar de mero reconhecimento de aspectos linguísticos, esvaziados de sentido, dificultando a inscrição do sujeito-aprendiz na língua e na cultura.

Para nós, é preciso trabalhar a historicidade, a interpretação, a trama de sentidos que tece os textos, a espessura material da língua. Acessar os discursos, como é o caso do discurso da comicidade, para refletir, deslocar, provocar estranhamento e produzir sentido (historicização) e não apenas "reproduzir". No caso que defendemos, não se trabalharia a língua como código, mas o equívoco constitutivo da relação língua/história, em seus 
processos de significação. Neste caso, o sujeito da prática escolar (tanto o aluno quanto o professor) estaria trabalhando o acontecimento da língua nele e não a língua como um instrumento. A comicidade (dos quadrinhos) seria um objeto produtivo na formação do aluno e do professor, constituindo-se em um exercício intelectual importante e não um mero receptáculo onde se alojam itens gramaticais descontextualizados.

Embora os textos pertencentes ao campo da comicidade sejam lugar de jogo de sentidos, de brincadeiras, o modo de abordagem dos LDs investigados cerceia o trabalho de interpretação, de movência dos sentidos e do sujeito. Ler um texto cômico é sempre um processo complexo, que exige exercício intelectual. Como se trata de um texto artístico verbo-visual que faz parte da sociedade em que vivemos e se constitui como um lugar de resistência, de liberdade, de estética do pensamento, faz-se necessário outro tipo de abordagem. Acreditamos que o modo de abordagem da comicidade deve transcender o objetivo de mero reconhecimento (localização) de verbos, estruturas linguísticas, temas e vocabulário. É preciso, pois, mudar as condições de produção já sedimentadas de leitura na escola, o que é possível por meio de uma mudança no que diz respeito à concepção de língua, de texto e de ensino-aprendizagem de uma língua. Em síntese, urge um tipo de abordagem que permita vislumbrar o funcionamento do texto, da língua, a fim de o sujeito vislumbrar e experimentar o movimento de sentido.

O tipo de abordagem que encontramos nos LDs pesquisados pode ter implicações sérias no ensino-aprendizado de inglês como LE, dado o papel relevante que o LD de língua estrangeira adquire na constituição da identidade de professores e alunos (PERUCHI; CORACINI, 2003), mesmo embora estejamos na era digital. Observamos, pelo menos, três consequências, principalmente para o aluno, de uma abordagem dos QHs pautada na leitura monossêmica e na língua enquanto código e mero conjunto de regras gramaticais. A primeira delas é o apagamento da criatividade, da imaginação, do prazer. A segunda, intimamente relacionada à primeira, é a total ausência do componente lúdico, do prazer cômico, do envolvimento que toda aprendizagem (entendida como aquela que atravessa o corpo e o transforma) deve pressupor. Finalmente, a terceira diz respeito ao apagamento do aspecto político da comicidade. Com Freud (1905), vimos que o campo da comicidade traz em seu bojo implicações sérias, políticas, isto é, os jogos e os embates com a memória e as posições ideológicas dos sujeitos. Na abordagem dos QHs pelos LDs pesquisados, esse caráter político é apagado.

O modo de ler os quadrinhos, instaurado pelos LDs investigados, é, assim, regulado por procedimentos de controle da interpretação que se materializam, em grande parte, em formas enunciativas - como é caso das práticas pedagógicas justapostas aos quadrinhos 
- que mergulham o aluno num espaço lógico-pragmático que tende a desambiguizar os sentidos, normatizando-os; mas também de impotência, de impossibilidade de produzir e experimentar sentidos de outro modo.

Para que haja historicização de sentidos, efeito e prazer cômico, para que o ensino de inglês por meio de QHs constitua uma experiência mobilizadora de questões linguístico-culturais e identitárias, é preciso uma mudança de posição: pensar a língua em seu funcionamento, ou seja, na sua relação constitutiva com a história (sóciocultural) para produzir sentido, e não como uma estrutura que funciona por si mesma, exterior ao sujeito. Só assim, o humornão será concebido como um mero momento de divertimento que não requer um exercício intelectual ou, simplesmente, concebido como lugar de reconhecimento, como já dissemos, de estruturas da língua, mas como elemento fundamental para a constituição da subjetividade, do sentido outro, possibilitando o estranhamento, o deslocamento de posições subjetivas e a criatividade que, exercida, poderá, um dia, permitir aos alunos atitudes singulares. 


\section{REFERÊNCIAS:}

ARROJO, R. (Org.). O Signo Desconstruído. Implicações para a tradução, a leitura e o ensino. Campinas, SP. Editora Pontes, 1992.

AUTHIER-REVUZ, J. Heterogeneidade(s) enunciativa(s). Caderno de Estudos Linguísticos, Campinas (SP), n.19, dez. 1990, p.25-42.

CIRNE, M. Bum! A explosão criativa dos quadrinhos. Petrópolis, RJ: Editora Vozes, 1970.

CORACINI, M. J. R. F.; BERTOLDO, E. S. (Orgs.). O desejo da teoria e a contingência da prática. Discursos sobre-na sala de aula e língua materna e língua estrangeira. Campinas, SP: Mercados de Letras, 2003.

CORACINI, M. J. R. F. (Org.). Interpretação, Autoria e Legitimação do Livro Didático. $1^{\circ}$ Ed. Campinas, SP: Pontes, 1999.

CORACINI, M. J. R. F. O jogo discursivo na aula de leitura. Língua materna e língua estrangeira. Campinas, SP: Pontes, 1995.

FERREIRA, M. C. L. Da ambiguidade ao equívoco: a resistência da língua nos limites da sintaxe e do discurso. Porto Alegre: Editora da Universidade do Rio Grande do Sul, 2000 .

FOUCAULT, M. (1979). Microfísica do poder. 16 ${ }^{\mathrm{a}}$. Ed. Rio de Janeiro, RJ: Graal, 2001.

FOUCAULT, M. Arqueologia do saber. Petrópolis; Lisboa: Centro do Livro Brasileiro, 1969.

FREUD, S. (1905). Os chistes e sua relação com o inconsciente. ESB, vol. VIII. Rio de Janeiro: Imago, 1988.

JELIN, I. English: a high school coursebook. São Paulo, SP: FTD, 1995.

KLAWA, L.; COHEN, H. Os quadrinhos e a comunicação de massa. In: MOYÁ, A. Shazam! São Paulo: Editora Perspectiva, 1972, p. 103-114.

MARQUES, A. Password: special edition. São Paulo, SP: Editora Ática, 1999.

MENDONÇA, M. R. S. Um gênero quadro a quadro: a história em quadrinhos. In: DIONISIO et al. (Org.). Gêneros textuais e ensino. Rio de Janeiro: Lucerna, 2005, p. 194-207. 
MOTA, I. O. Humorless approach: análise discursiva de quadrinhos de humor em livros didáticos de inglês como língua estrangeira. São Paulo, SP: Editora Appris, 2018.

ORLANDI, E. Discurso e texto: formulação e circulação dos sentidos. Campinas, SP: Pontes, 2001.

ORLANDI, E. Análise de discurso - princípios e procedimentos. Campinas, SP: Editora Pontes, 1999.

PÊCHEUX, M. (1980). Ler o arquivo hoje. In: ORLANDI, E. (Org.). Gestos de Leitura. Da História no Discurso. 2a . Ed. Trad. Maria das Graças Lopes Morin do Amaral. Campinas, SP: Editora da Unicamp, 1997, p. 55-64.

PERUCHI, I.; CORACINI, M. J. F. R. O discurso da cultura e a questão da identidade em livros didáticos de francês como língua estrangeira. In: CORACINI, M. J. (Org.). Identidade e Discurso. Campinas, SP: Editora da Unicamp; Chapecó: Argos Editora Universitária, 2003, p. 363-385.

RAMOS, R. C. G. O Livro Didático de Língua Inglesa para o Ensino Fundamental e Médio: Papéis, Avaliação e Pontencialidades. In: DIAS, R.; CRISTÓVÃO, V. L. (Orgs.). O Livro Didático de Língua Estrangeira. Múltiplas Perspectivas. Campinas, SP: Mercado de Letras, 2009, p. 173- 198.

SOUZA, D. M. Autoridade, Autoria e Livro Didático. In: CORACINI, M. J. (Org.). Interpretação, Autoria e Legitimação do Livro Didático. $1^{\circ}$ Ed. Campinas, SP: Pontes, 1999, p. 27-31. 